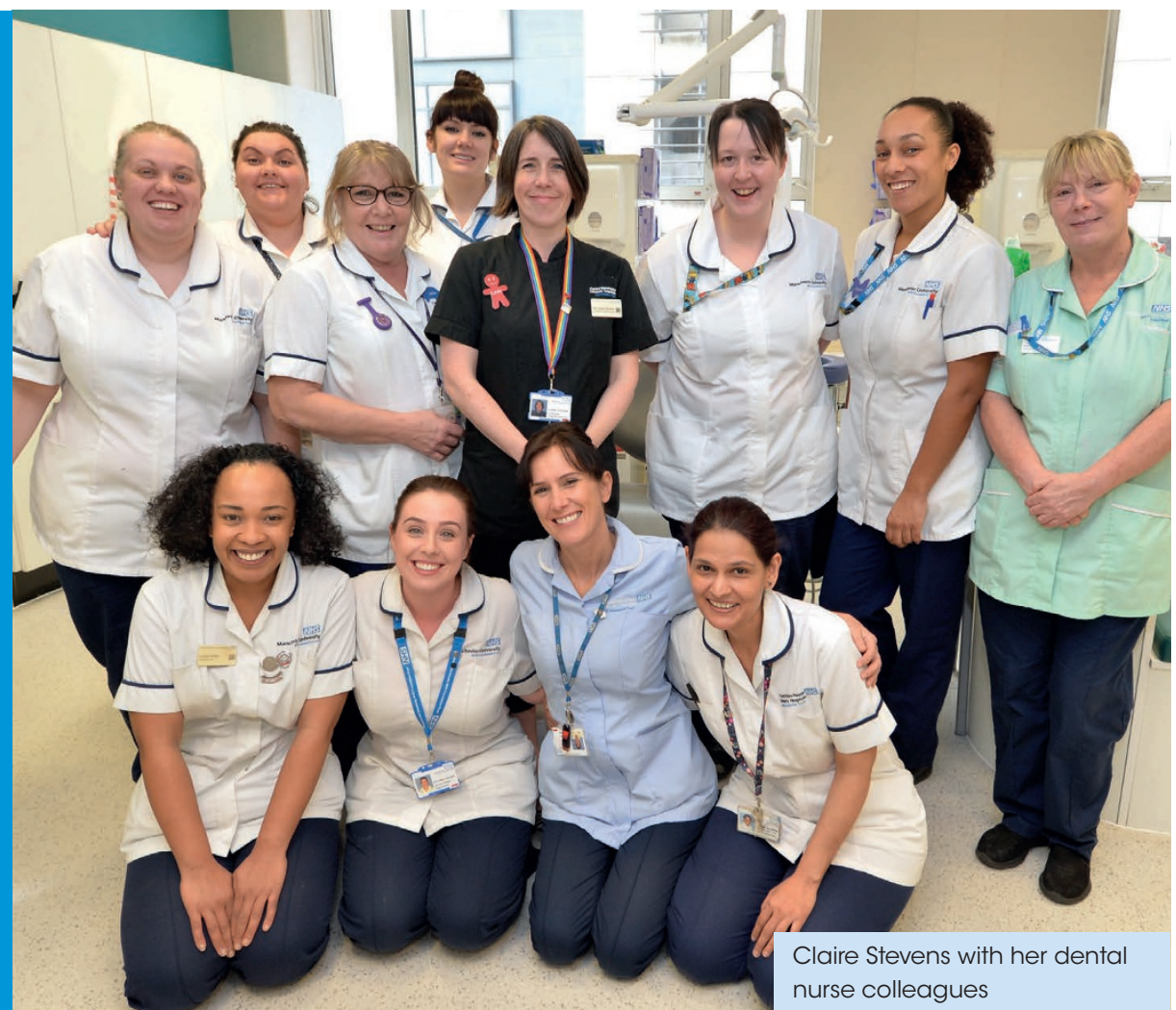

\section{ADVOCATE FOR CHILDREN'S ORAL HEALTH AWARDED CBE}

Claire Stevens - aka the Toothfairy - has been appointed a CBE - Commander of the British Empire- in the Queen's New Year's Honours List in recognition of her commitment to improving children's oral health. The British Society of Paediatric Dentistry, for whom she is official spokesperson and immediate past President, says it is 'proud beyond measure'.

She is to be awarded the highest of the three orders of the British Empire, recognising the importance of children's dentistry, her work for BSPD and the commitment she has shown to being an advocate for children's oral health.

In her day job, working as a Consultant in Paediatric Dentistry in Greater Manchester's Health and Social Care Partnership, she has made her mark. Jon Rouse, Chief Officer of GMHSCP, supported her nomination for recognition in the Honours List. She is the chair of the Managed Clinical Network for Paediatric Dentistry in Greater Manchester and an expert advisor to the Brush DJ app.

In her day job, Claire has taken a lead role in ensuring that the whole child is assessed, not just the teeth, working with her team to signpost families onto other services. She has been instrumental in connecting her hospital with a programme designed to reduce obesity in Greater Manchester's children. As a result, many of those working with children in the city and beyond are sharing important key messages in relation to diet and oral hygiene.

A mother to two young children and the founder of the Toothfairy blog (www. toothfairyblog.org), she has thrown herself both personally and professionally into reversing the tide of general anaesthetics for multiple extractions in children.

Claire commented: 'This award feels momentous because it has been made for services to children's oral health. At last we are recognising the importance of supporting every child to grow up free of dental disease.'

'I am the public face of the campaign to improve children's oral health, but this isn't just about me. Others have smoothed the way, and I am privileged to work alongside many people who continue to dedicate their lives to improving children's health. My advocacy has only worked thanks to all those who collaborate and work with me, in BSPD, in Greater Manchester and within the profession. To them I pay tribute.'

\section{STRESS IN DENTISTRY}

More than

half of dentists say stress is affecting their practice according to a study undertaken by the BDA and published in the BDJ (https:// www.nature. com/articles/

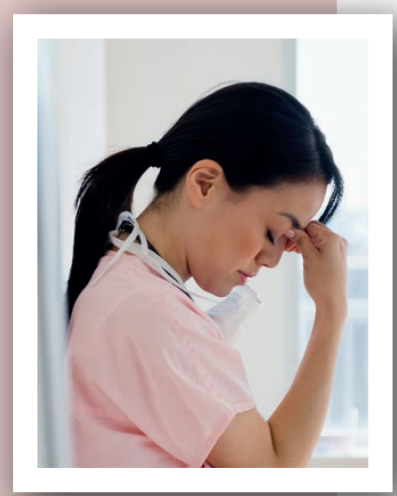

sj.bdj.2019.6). Around 2000 dentists enrolled in the study of whom $44 \%$ said they could not cope with the level of stress and more than $17 \%$ said they had seriously considered suicide. One of the authors, Dr Vicki Collins, a BDA Research Analyst said that some aspects of regulation and fear of litigation were key concerns.

Stress at work is not limited to dentists. In this issue of BDJ Team we feature an article by Cary Cray-Webb who handed in her resignation at her workplace due to intolerable stress. Among the steps that could be taken to reduce stress in the dental workplace, she suggests, would be allowing more breaks and shorter shifts. To read Cary's article, turn to page 13.

\section{Ereater}

MANCHESTER DOING IT

\section{DIFFERENTLY}

\section{Thousands of young children are to} benefit from a new $£ 1.5 \mathrm{~m}$ programme aimed at transforming the dental health of under-fives across Greater Manchester. Launched last month by Greater Manchester Health and Social Care Partnership, the body overseeing devolution of health and care services, the fresh initiative will see supervised toothbrushing introduced in schools and nurseries plus dental care incorporated into health visitor checks in areas where particularly large numbers of young children suffer from tooth decay. 